\title{
AI Works Protected by the Laws of the International Situation and Enlightenment
}

\author{
Sun.Yuang ${ }^{1}$ \\ ${ }^{1}$ Yantai University Law School, Yantai Shandong China 264010 \\ Author's Email:849815233@qq.com

\begin{abstract}
At present, a large number of works of artificial intelligence impact on human cognition and countries also put it into creation is a necessary arrangement. The European parliament is proposed in the draft legislation that artificial intelligence can be identified into the law, giving these artificial intelligence copyright, labor rights and particular rights. Japan's legislative discussion tends to artificial intelligence works about the rights and interests by individuals or enterprises enjoy. The United States has not formed a more unified opinion on the ownership of the copyright of artificial intelligence works. In the discussion of the world intellectual property organization, artificial intelligence works copyright shall be awarded to the program designer.
\end{abstract} \\ legal measures to cope with this situation. In the UK, artificial intelligence's copyright belonging to the work of
}

Keywords: Artificial intelligence works, Copyright protection, International legislation present situation

\section{INTRODUCTION}

In May 2017, Microsoft co-produced a collection of poems, "the sun has gone out of the window". [6] The biggest highlight is that it is not written by humans, but artificial intelligence products --Microsoft $\mathrm{s}$ ice cube. Now, more diverse artificial intelligence works have emerged. For example, Sony's Flow Machines wrote a Beatle-style song and "Daddy Cars" and International Business Machinesé created a" Cognitive Movie Preview'. A slightly soft-artificial Rembrandt analyzed more than 300 of his paintings and created an extreme work for the suspenseful horror film Morgan. Narration science even thinks that the vast majority of news stories will soon be written by artificial intelligence. Mankind is entering the era of artificial intelligence[1]. Under the background of globalization, in face of the common impact of artificial intelligence works on human beings, it is necessary for countries to establish regulations to draw on each other's strengths and supplement their weaknesses. The purpose of this paper is to provide some references for Chinese legal regulation of artificial intelligence works by referring to foreign experiences.

\section{THE INTERNATIONAL STATUS OF LEGAL PROTECTION ABOUT ARTIFICIAL INTELLIGENCE WORKS}

\section{1. $U K$}

At present, in the world's major developed economies, the United Kingdom of Great Britain and Northern Ireland have made clear legal provisions on the copyright of artificial intelligence works. Article 9, paragraph 3 of the copyright act was enacted in 1988 . The United Kingdom attributed copyright in the work of artificial intelligence to the person making the necessary arrangements for the creation of that work. [3] The term "computer-generated writing, comedy, musical or artistic works" in this article is limited to works produced by the computer environment itself without the participation and intervention of any person. And artificial intelligence work's protection period is different from general work, for its publication date to the last day after 50 years of counting from publication year. It is worth noting that the Copyright Act of the United Kingdom while protecting the copyright of works by artificial intelligence, denies that such works contain a personal right to authorship. 


\subsection{Us}

The National Council on the Use of New Technologies in Copyright Works (CONATU) in a report published in 1978, identified the authors of artificial intelligence works as the people who created them, not as artificial intelligence itself, but this is not formal legislation. Up to now, the United States has no ready legislation on artificial intelligence works. From the point of view of practice, it has not implemented the conclusions of the report. Before 1993, the United States Copyright Administration registered and granted copyright to two copyrighted works generated by computer software[3]. In its registration, the United States Copyright Office awarded the copyright to the two writings to programmers, rather than to users of artificial intelligence as indicated in CONTU's 1978 report, who even considered computer software to be the actual author of the facts. The United States does not exist at present to artificial intelligence work. Copyright belongs to a more unified opinion.

\subsection{The European Union}

No relevant laws and regulations on copyright regulation of artificial intelligence work in the European Union, but there are plans for legislation. As early as 31 December 2012, the European Association for Coordinated Action on Artificial Intelligence published the Green Paper on Legal Issues in Artificiality (Green Book). Its fourth part argues that the current intellectual property regime is based on the fact that computers are only aid to human production and life, and therefore that IP laws regulate only the creation of natural or legal persons. But with the development of artificial intelligence, the intellectual property law should be adjusted to protect the IP of AI creations.[2]

The green paper also suggests that, based on incentive theory, it would be more appropriate to license artificial intelligence works to those who provide material support such as financial and logistical support for the production of the robot's work. On 31, May 2016, the Commission's Legal Affairs Committee began responding to the proposal of the European Association for Coordinated Action on artificial intelligence by proposing a motion for the creation of a copyright provision for human intelligence works, which would require the establishment of an artificial intelligence register to open financial accounts covering legal liability for these robots. On February 16, 2017, the European parliament passed a draft report to the commission proposing legislation on the rules of civil law on robotics, reflecting the motion which would give artificial intelligence copyright[5]. The draft further proposes that the most advanced artificial intelligence can be recognized as a legal subject and given specific rights such as copyright and labor rights. Interestingly, on January 22, 2018, at the International Conference on Digital Life Design (DLD) in Munich, Germany, Maria Gabriel, the European Commission's commissioner for digital economy and society, announced that EU countries would begin drafting laws on artificial intelligence starting in the spring of 2018. But so far the EU is still only in the legislative phase of the early stage, the formal enactment of relevant laws and regulations will take some time.

\subsection{WIPO}

The revision of the Bern Convention for the Protection of Literary and Artistic Works was discussed by the WIPO Committee of Experts in 1991. In the original version of the discussion, computer creations were included in the category of works but were eventually excluded[4]. In the original version of the discussion, the copyright in work of artificial intelligence was stated as follows: "A work created by a computer refers to work in which human ingenuity is so insignificant that it is not sufficient to make the human being the author required by copyright law. The copyright belongs to a person who performs the necessary operations for the creation of that work, and whose copyright does not include the personality right." In October 2017, WIPO held another discussion on the protection of AI works in its publication. The first was that AI works should not be copyrighted, because AI is not the author of copyright law. It adheres to the traditional theory of Copyright Law and believes that works must reflect the personality of their authors. The second view is that artificial intelligence works should be protected by copyright law and their copyright should vest in the designer of artificial intelligent programs.

\section{ARTIFICIAL INTELLIGENCE COPYRIGHT PROBLEMS}

The purpose of copyright law in China is to protect the copyright and related rights and interests of the authors of works in the fields of literature, art and science. Whether artificial intelligence products can be regarded as works, how to determine the ownership of their copyright is still in doubt in copyright theory. [7]The traditional copyright law is centered on "man", and creation is the exclusive activity of" person'. The author is equal to the natural person, such as the "principle of creator" adhered to in German, which also stipulates that citizens are the authors of works. In the process of literary and artistic creation with "human" as the main body, human feelings are combined, which has the unique creativity of human beings, and the addition of artificial intelligence undoubtedly expands the existing legal framework. Artificial intelligence products can not reflect what people think and feel about the environment and experience in the process of output, but content presented by AI can also arouse people's 
sympathies. With the development of technology, it is more and more difficult to distinguish whether the works come from man or AI. With the rapid development of artificial intelligence technology, today's AI has a more human way and level of thinking. But in fact, it is difficult to reach this conclusion even in the more advanced areas of deep learning. The current view is that deep learning is "mimicking the human brain." That's debatable because while it draws inspiration from biological mechanisms, it is a far cry from how the brain works. Therefore, to solve the predicament of artificial intelligence in copyright law, we should recognize the stage of development, based on the present situation, and put forward a reasonable plan.

\section{CONCLUSION}

It can be seen from the current legislation and legislative activities of developed economies and world organizations on copyright protection of artificial intelligence works that only the United Kingdom has made relatively complete legal provisions. Although British law states that artificial intelligence can produce works on their own, the copyright of their works will eventually be granted to the self-employed[5]. Because the authorship of works is based on the principle of motivation, the person who created the works needs to be motivated. Therefore, at the present level of artificial intelligence, it is meaningful to award artificial intelligence works to natural talents. Moreover, given that the current AI lacks a civil personality, the copyright in work of artificial intelligence under the British copyright law does not include the right to the personality of work.

It should be noted that the British copyright law on artificial intelligence works dates back to 1988 when it was already very forward-looking[6]. Although there is no formal copyright law on artificial intelligence works in other countries, their motions, drafts and legal practices are worthy of reference. For example, the suggestion of artificial intelligence fund account of the EU is suitable to solve the problem of intellectual property infringement. The proposal of Japan's legal registration system, anti-unfair competition law protection and the limitation of the object protected by the copyright law of man-made works are also worthy of our reference. To sum up, the world's copyright legislation on artificial intelligence works is basically at the frontier stage. Its essence lies in that in the past, so-called artificial intelligence often needs to be operated mainly by human beings, and the artificial intelligence which can self-study and self-operate to produce results was born with the rapid development of science and technology in recent two years. In the future, with the legislation of various countries, the vacuum of artificial intelligence works will gradually be regulated by laws and regulations, and China should follow the world's footsteps and formulate laws on the copyright protection of works in artificial intelligence.

\section{ACKNOWLEDGMENT}

First of all, I would like to extend my sincere gratitude to my supervisor, Sonia K Katyal, for her instructive advice and useful suggestion on my thesis. I am deeply grateful for her help in the completion of the thesis. I am also deeply indebted to all the other tutors and teachers, the TA Shen yuan and the English teacher Olivia Sun. They devoted teaching and enlightening lectures I have benefited a lot and academically for the thesis.

\section{REFERENCES}

[1] Mark Perry, Thomas Margoni. From music tracks to Google maps: Who owns computer generated works?[J]. Computer Law \& Security Review, 2010(6):621-622.

[2] Erica Fraser, Computers as Inventors-Legal and Policy Implications of Artificial Intelligence on Patent Law, SCRIP Ted, 2016

[3] Song Haiyan. Artificial Intelligence and Copyright Talk[J]. The Chinese press, 2018 (1): 34

[4] Zhang Chaojun. Research on Copyright Protection of Artificial Intelligence Creations[D]. Shandong University School of Law, 2018.

[5] Li Ben. Artificial Intelligence in American Judicial Practice: Issues and Challenges[J]. China Law Review, 2018 (02).

[6] Huang Cheng. International Status and Enlightenment of Legal Protection of Artificial Intelligence Works[J]. China National Conditions and Strength, 2021 (01): 56-58.

[7] Cha Zhen. Study on Patent Protection of Artificial Intelligence Algorithms[J]. CO-Operative Economy \& Science, 2021 (03): 190-192. 